\title{
FLIGHTLESSNESS AND FOLIVORY IN HAWAII'S EXTINCT TERRESTRIAL WATERFOWL
}

JAMES, Helen F., Dept. of Vertebrate Zoology, National Museum of Natural History, Smithsonian Institution, Washington, DC 20560, U.S.A.; BURNEY, David A., Dept. of Biological Sciences, Fordham University, Bronx, NY 10458, U.S.A.

The highly endemic plant communities of the Hawaiian Islands were once thought to have evolved in the absence of significant browse pressure from vertebrate herbivores, a view that is challenged by the discovery of six species of large subfossil waterfowl (Anatidae). Hawaiian waterfowl were not restricted to wetlands and grasslands, but were widely distributed in terrestrial habitats before their extinction. Radiocarbon determinations on bones from most of these species place their extinction in the late Holocene, and implicate prehistoric human ecological impacts as the cause. Five of the six species were flightless. The ecological role of these birds and the possible ecological consequences of their loss from native ecosystems have only recently begun to be assessed.

We obtained a collection of coprolites from Thambetochen chauliodous, one of four species of flightless Hawaiian waterfowl known collectively as moa-nalos. Pollen/spore spectra from the coprolites indicate that ferns were important in the diet, supporting the contention that these birds were primarily folivorous. The coprolites are composed of fine particulates and appear to have contained relatively little macroscopic plant fiber when they were fresh. This suggests that the gastrointestinal tract was specialized for efficient fermentation and digestion of fiber.

Ancient DNA sequences from subfossil moa-nalos indicate that their evolutionary relationships lie with the dabbling ducks, tribe Anatini. Compared with typical dabbling ducks, the moa-nalos are characterized by large body size, a very heavy lower body, and extreme reduction of tissues associated with flight. These anatomical features can be understood as adaptations to a bulky, low-quality diet.

True geese are members of another branch of the family Anatidae, the tribe Anserini. Like the moa-nalos, true geese feed mainly on leaves and other plant parts in terrestrial habitats, yet they retain the ability to fly. The digestive system in true geese is characterized by a fairly simple gut and rapid throughput times of the digesta. By rapidly processing a great deal of plant material, the geese obtain a fairly high-energy diet from plant cell contents while excreting much of the plant fiber. The modifications seen in the moa-nalo skeleton suggest that the moa-nalos had evolved a greater degree of specialization for fermentation and digestion of cell wall constituents, a process that is aided by long retention of heavy and bulky digesta in the gut.

A diet rich in ferns is plausible in Hawaii, where ferns are common in most native habitats and fern spores are abundant in Holocene sediment cores. It has been suggested that the moanalos fed on other plants as well, and may have influenced their evolution. A recent hypothesis of plant-herbivore coevolution in Hawaii postulates that the thorn-like prickles and dissected foliage present in certain endemic lobelias (Campanulaceae: Cyanea and Rollandia) evolved in response to natural selection by the moa-nalos. 